\title{
Emergent trends and passing fads in project management research: A scientometric analysis of changes in the field
}

\author{
Julien Pollack*, Daniel Adler \\ University of Technology Sydney, PO Box 123 Broadway, NSW 2007, Australia
}

Received 25 September 2013; received in revised form 14 April 2014; accepted 29 April 2014

Available online 28 May 2014

\begin{abstract}
This research uses quantitative techniques to reveal trends in project management related research published between 1962 and 2012 . The data set for this research includes 94,472 unique records sourced from the Scopus and ISI Web of Science databases. The keywords and abstracts that authors have used to describe their work have been analysed in terms of word frequency, rate of change and the co-occurrence of keywords and abstract terms. This data has been used to construct network maps of the field, depicting the relative association between key topics. Comparisons are made between the frequencies of key terms and rapid changes in the ways that terms are used in the literature to identify emergent trends and passing fads. Amongst other findings, this research has revealed evidence to indicate a change in emphasis in project management research from a technical engineering orientation to one which encompasses a broader organisational perspective.
\end{abstract}

(C) 2014 Elsevier Ltd. APM and IPMA. All rights reserved.

Keywords: Trends; Research; Scientometrics; Fads; Literature analysis; Bibliometrics

\section{Introduction}

Project management (PM) is a diffuse field of research, contributed to by practitioners and researchers publishing in a wide variety of sources, from journals exclusively focusing on $\mathrm{PM}$, to publications targeted to the specific industries or areas of application where projects are managed. Research into PM continues to change, a phenomenon which can be attributed to developments in the body of knowledge, but also to the multi-disciplinary nature of the field, and the expansion of PM into new practice domains. In addition, "Fad effects affect the field of project management..." (Urli \& Urli, 2000, p. 40), lending additional diversity to PM research, as academics draw on learning from related disciplines to address new issues in the field.

However, it can be difficult for an individual to develop a holistic perspective of the whole of project management research. Individual researchers tend to remain entrenched in local research

\footnotetext{
* Corresponding author.

E-mail addresses: Julien.pollack@uts.edu.au (J. Pollack),

Daniel.adler@uts.edu.au (D. Adler).
}

collaborations and institutional boundaries, focusing on necessarily myopic research topics, and the particular research papers that result from a limited range of search terms. It can become difficult to perceive the emergent changes in a field from a small number of its parts. Other authors have noted that "...changes in the contexts for project management are an important consideration for research" (Carden \& Egan, 2008, p. 7), providing benefit to those who seek to understand how the field as a whole is developing.

The research presented in this paper will particularly be of interest to academics, researchers and research students interested in understanding how research into project management is changing. This research will be of interest to management consultants looking to anticipate changes to the field, while it is also anticipated that the methodological findings will be of interest to the scientometric research community.

\section{Previous research}

Developing an understanding of the ways in which a whole field of research is developing is a problematic issue which a 
wide variety of authors has considered important. Evidence for this can be seen in the large number of previous articles which have addressed aspects of this issue, and the variety in techniques authors have employed. The earliest study of changes in project management research was conducted by Betts and Lansley (1995), who reviewed publications from 1983 to 1992 in the International Journal of Project Management (IJPM). This study used an a priori classification of publications, and an analysis of how frequently individual authors and institutions contributed to the journal. Comparable analyses of changes in PM research were made by Themistocleous and Wearne (2000) and Zobel and Wearne (2000), two papers which used the same methods to classify PM research. The first of these papers classified articles published between 1984 and 1998 in IJPM and the Project Management Journal (PMJ), while the second focused on four PM conferences that were held between 1996 and 1997. Both papers classified research according to its alignment with the Association for Project Management's Body of Knowledge.

Prior to the research presented in this paper, the three largest studies enquiring into general trends in PM research were arguably those conducted by Urli and Urli (2000), Kloppenborg and Opfer (2002), and Crawford et al. (2006). Urli and Urli (2000) studied PM research in the ABI-Inform database from 1987 to 1996. Their research brought together 3565 PM-related articles using a scientometric keyword analysis technique. Kloppenborg and Opfer (2002) also drew upon the ABI-Inform database, amongst other sources, to review PM research from 1960 to 1999 , in a study which has been referred to as "...the most comprehensive review to date of the project management literature..." (Carden \& Egan, 2008, p. 7). Their research also involved workshops to review the abstracts of 3554 records, categorising research against PMBOK Guide (PMI, 1996) knowledge areas and process groups. Crawford et al. (2006) also enquired into changes in keyword use, this time from IJPM and PMJ articles from 1994 to 2003 using a keyword analysis technique based on corpus linguistics and an a priori classification based on competency based standards. Their paper is also significant in that it is one of the few that have attempted to consolidate the findings from earlier studies.

More recently, Carden and Egan (2008) conducted a qualitative study of the literature, reviewing a selection of publications that the authors considered relevant from non-traditional industries published from 1968 to 2004. Kwak and Anbari (2009) have also recently conducted research into the content of publications in 18 general management and business journals from 1950 to 2007, grouping articles relevant to PM according to eight categories. Similarly, Söderlund (2011) has reviewed the content of 30 journals from general management and allied disciplines, identifying seven different schools of thought in project management research. Other comparable research has been conducted by Artto et al. (2009) and Hanisch and Wald (2012); however these papers have limited the scope of their research to a small subset of publications, focusing on program management in the former case and theoretical perspectives in the latter. Biedenbach and Müller (2011) applied an a priori classification method to reflect on research presented at the IRNOP (International Research Network on Organising by
Projects) conferences held in 1994, 2000 and 2007 to investigate the relationship between research methods, epistemology, and ontology. Other recent studies of the PM literature focusing on trends in how PM research is conducted include those by Smyth and Morris (2007) and Söderlund (2004a, 2004b).

As previously identified by Crawford et al. (2006), review of this literature reveals not just the variety of research that has been conducted into changes in PM research, but also the number of different methods that have been used. A criticism that can be raised against some of the previous research relates to the use of a priori, rather than emergent, classification systems. In using an a priori classification system, researchers attempt to understand their findings through categories they have brought to the research, rather than ones that are directly related to the research data. A consequence of this approach is that new developments are communicated through earlier dominant structures, which may limit the ability of the researcher to see or communicate significant developments which fall between or outside pre-determined categories. An exception to this is the study by Urli and Urli (2000) who used scientometric techniques to uncover "...the most significant themes as defined by academics themselves rather than by an a priori classification" (p. 34). The research presented in this paper builds on Urli and Urli's study, using similar scientometric techniques across a broader time scale and range of sources. Key characteristics of previous studies have been summarised in Table 1.

Three key factors distinguish the research presented in this paper from previous studies. This research draws on a considerably larger data set, over a longer period, than previous studies. Unlike most of the earlier research, this paper has not distinguished between sources specific to project management or sources from specific industries, arguably allowing the data to provide a more accurate perspective on the field as a whole. Furthermore, unlike many previous studies, this research has not applied an a priori classification system, instead letting the findings emerge directly from the research data.

\section{Research methodology}

This research provides a holistic analysis of the field of project management research using scientometric techniques, a research method which has also been referred to as knowledge domain visualisation or domain mapping (Hook \& Börner, 2005), and can be considered a part of the more general field of information visualisation (Hook, 2007: 442). It is a quantitative method, used to study academic and other scientific publications, which has emerged from citation based domain visualisation (Chen et al., 2011: 131). Scientometric research aims to provide:

"...the graphic rendering of bibliometric data designed to provide a global view of a particular domain, the structural details of a domain, the salient characteristics of a domain (its dynamics, most cited authors or papers, bursting concepts, etc.) or all three" (Hook \& Börner, 2005: 201).

Given the volume of data available to researchers, images of changes and developments in academic disciplines help to support 
Table 1

Studies of trends in project management.

\begin{tabular}{|c|c|c|c|c|c|}
\hline Study & Size & Period & Source & Method & Classification \\
\hline Betts and Lansley (1995) & 347 Papers & $1983-1992$ & IJPM & Frequency analysis & A priori - industry and topic \\
\hline Themistocleous and Wearne (2000) & 748 Papers & 1984-1998 & IJPM and PMJ & Frequency analysis & $\begin{array}{l}\text { A priori - APMBoK and PMBoK } \\
\text { Guide }\end{array}$ \\
\hline Zobel and Wearne (2000) & 633 Papers & 1996-1997 & $4 \mathrm{PM}$ conferences & Frequency analysis & $\begin{array}{l}\text { A priori - APMBoK and PMBoK } \\
\text { Guide }\end{array}$ \\
\hline Urli and Urli (2000) & 3565 Papers & $1987-1996$ & ABI-Inform & $\begin{array}{l}\text { Scientometric, centrality, } \\
\text { density }\end{array}$ & A posteriori — authors' keywords \\
\hline Kloppenborg and Opfer (2002) & 3554 Papers & 1960-1999 & $\begin{array}{l}\text { ABI-Inform, Compendex, } \\
\text { Infotrac, Digital Dissertations }\end{array}$ & $\begin{array}{l}\text { Literature review, facilitated } \\
\text { workshops }\end{array}$ & $\begin{array}{l}\text { A priori — PMBOK Guide, } \\
\text { industry and process }\end{array}$ \\
\hline Crawford et al. (2006) & 1051 Papers & 1994-2003 & IJPM and PMJ & $\begin{array}{l}\text { Keyword analysis, corpus } \\
\text { linguistics }\end{array}$ & $\begin{array}{l}\text { A priori - based on } \\
\text { competency-based standards }\end{array}$ \\
\hline Smyth and Morris (2007) & 68 Papers & 2005 & IJPM & Literature review & $\begin{array}{l}\text { A priori — based on research } \\
\text { methodology }\end{array}$ \\
\hline Carden and Egan (2008) & 90 Papers & $1968-2004$ & Emerald, IJPM, PMJ & Literature review & Thematic categorisation \\
\hline Kwak and Anbari (2009) & 537 Papers & $1950-2007$ & 18 General management journals & Literature review & A priori — based on prior studies \\
\hline Artto et al. (2009) & 1681 Papers & $1986-2006$ & 23 Business journals & $\begin{array}{l}\text { Co-citation analysis and } \\
\text { literature review }\end{array}$ & $\begin{array}{l}\text { A posteriori - based on author } \\
\text { keywords }\end{array}$ \\
\hline Biedenbach and Müller (2011) & 116 Papers & $\begin{array}{l}1994,2000 \\
2007\end{array}$ & IRNOP conferences & Content analysis & $\begin{array}{l}\text { A priori - based on research } \\
\text { paradigm }\end{array}$ \\
\hline This research & $\begin{array}{l}94,472 \\
\text { Papers }\end{array}$ & $1962-2012$ & ISI Web of Science and Scopus & $\begin{array}{l}\text { Scientometric frequency } \\
\text { and burst analysis }\end{array}$ & $\begin{array}{l}\text { A posteriori - author keywords } \\
\text { and abstracts }\end{array}$ \\
\hline
\end{tabular}

the communication and exploration of data (Börner, 2012: 430). "Just like old sea charts, maps of science can help people to find places of interest while avoiding monsters. They complement local fact retrieval via search engines by providing global views of large amounts of knowledge" (Börner, 2007: 808-9). Scientometric techniques have been used to identify the actors that are driving scientific advancement, whether they are institutions, research communities, or individuals (Scharnhorst, 2012: xii). Visualising project management research as a whole provides an opportunity to develop a holistic account of publications in the field.

The published literature on PM provides tangible evidence of developments in the field, which can lead to conclusions about influential works, authors, and institutions, about the kinds of research that is done, and the areas in which this work is applied. As PM is an interdisciplinary area of enquiry, it was considered important to understand the kinds of research that contributes to the field, as described by the authors themselves. Building upon the a posteriori approach used in previous studies of project management research (e.g. Artto et al., 2009; Urli \& Urli, 2000), this quantitative interpretivist research focuses on the text that authors of research have used to describe their own work.

There are three main fields that authors typically use to describe a publication: the title, the abstract, and keywords. The title of research papers was rejected as a unit of analysis, on the basis that titles are often written to attract initial reader interest, rather than to summarise a work in its entirety. Keywords and abstracts are typically used by authors to provide the prospective reader with a clear and concise description of the research content, and this provided useful indicators of changes in the field for the purposes of this research. It is acknowledged that there are limitations to using keywords and abstracts as units of analysis, as some publishers require authors to pick from a selection of possible ill-fitting keywords, while in other cases keywords may be applied post-hoc by a publisher more interested in consistency between the records in their database. In order to retain the authors' meaning as much as possible, the authors' keywords were used where present. Index keywords were supplemented only where necessary. Abstracts are also typically written according to publishers' requirements, which may constrain an author's expression of their research content. However, it was considered that aggregate keywords and abstracts would provide a useful perspective on how the field is changing.

In this research, the literature on PM has been analysed in terms of:

1. The keywords that authors use to describe their publications, in terms of frequency, change over time and tendency of association with other keywords; and

2. The abstracts that authors use to summarise their work, in terms of term frequency and change over time.

The research method was structured in terms of Börner's (2010: 51) scientometric workflow design:

1. Data acquisition and pre-processing

2. Analysis and modelling

3. Communication, visualisation and layout

This research used the $\mathrm{Sci}^{2}$ tool v1.0 Alpha ( $\mathrm{Sci}^{2}$-Team, 2009), a scientometric research and modelling suite. The researchers used ISI WoS and Scopus as the sources of research data. At the time of writing, the ISI WoS database included over 12,000 journals, 110,000 conference proceedings, 87 million source items, and 700 million cited references, from 256 scientific disciplines (Thompson-Reuters, 2012). Scopus included 19,500 peer-reviewed journal, 5.3 million conference papers, and 49 million records (Elsevier, 2013). It has been identified as "...hard if not impossible to identify and compare the entities 
(records and authors) from all contributing domains" (Börner, 2007: 814) and it is acknowledged that the combination of these databases does not include all publications that contribute to PM research. However, both of these databases include a significant number of publications relevant to applied management. The combination of sources from these two databases was considered sufficient to justify broad conclusions about the development of the field as a whole.

\subsection{Data acquisition and pre-processing for all analyses}

Data was retrieved from the ISI WoS database using the search term "project management" in the category "topic," the widest ranging search field available. Data was retrieved from the Scopus database using the search term "project management" for all fields. Both databases included records with keywords and abstracts from 1962 to 2012. The combined citation details provided by these searches formed the data set for this research ("the data set").

A summary of the results of these searches is listed in Table 2. It is interesting to note that there were a considerable number of duplicate records both within and between Scopus and Web of Science. In order to resolve this issue, records from both databases were first combined and filtered based on matching authors, title, abstract and year of publication. This had the effect of reducing the total records by $8.9 \%$. Incomplete fields within records also reduced the usable data set for some specific analyses, as listed in Table 2 . It is of interest to note that $77 \%$ of the records included the term "project" in the title, 35\% included the term in the abstract, while it occurred in $79 \%$ of keyword lists. The source breakdown of the data set was as follows: conference papers, 42\%; journal articles, 37\%; reviews, 10\%; not specified, $5 \%$; short survey, $2 \%$; note, $1.5 \%$; book or book chapter, $1 \%$; other, $1.5 \%$.

Significant manual work was required to reconcile minor differences between the spelling of keywords and to normalise abstract text. Keyword and abstracts lists were also edited to remove terms that did not add significant meaning. For instance, the keyword "project management" was removed as not adding value to this research. The majority of punctuation and capitalisation was also removed from keywords. Proper nouns were also typically deleted from keyword and abstract text lists, such as the names of publishers and institutions. Both authors independently worked on this process before negotiating an agreed set of data set changes, in order to improve reliability. Börner (2010: 50) has described this phase of scientometric research as time consuming, that about "...80 percent of a typical project's total effort is spent on data acquisition and preprocessing..."

Table 2

Valid records within the data set.

\begin{tabular}{lc}
\hline Field & Number of records \\
\hline Original search of Scopus (Elsevier) & 96,541 \\
Original search of Web of Science (ISI) & 8860 \\
Data set without duplicate records & 94,472 \\
Records with complete "Keyword" and "Year" & 86,691 \\
Records with complete "Abstract" and "Year" & 90,979 \\
\hline
\end{tabular}

Ensuring the integrity of the data would have taken at least this percentage of the research project's time.

Following acquisition and preprocessing, analyses of Keyword Co-Occurrence, Keyword Burst Detection, Abstract Burst Detection and Abstract Frequency were conducted. Methodological considerations with each of these steps will be considered separately below.

\section{The keyword co-occurrence network}

Network analysis was done using the $\mathrm{Sci}^{2}$ tool, and the initial network characteristics are listed in Table 3. Nodes in the Keyword Co-Occurrence Networks represented individual keywords used by authors to describe their work. Network edges represent the co-occurrence of a keyword in a single record, where two specific keywords are used together to describe a research publication.

Due to computational constraints at this scale of relief, it was not technically possible to visualise this network in its entirety. $\mathrm{Sci}^{2}$ provides several methods of pruning networks based on node and edge attributes. Node attributes are, for example, the frequency with which a keyword have been used, while edge attributes included the number of times two keywords have been used in combination. In this case, the network was trimmed based on keyword co-occurrence.

The next step in this process was to visualise the Keyword Co-Occurrence Network. It was found that by keeping only edges with a weight of greater than twenty, and removing resultant isolate nodes, it was possible to visualise the network using Guess network visualization software, part of the $\mathrm{Sci}^{2}$ suite of tools. This left a network of 775 nodes. The graph visualisation was created using the Graph EMbedding (GEM) algorithm (Frick et al., 1994: 338). GEM positions nodes and edges using a type of spring-embedding algorithm. Node and edge positions are non-arbitrary, with edges drawing nodes together, like springs, while the nodes repel each other. This algorithm results in a representation where the more central nodes tend to visually central to an image, with a minimum of crossed edges. Nodes that are strongly associated will be placed closer together, while less associated nodes will be placed further apart. Images were also edited with Photoshop for publication. Fig. 1 shows the largest cluster in the Keyword Co-Occurrence Network. Node size represents the frequency with which a keyword occurs in the data set. Edge weight represents the frequency with which two keywords have been used in combination.

Fig. 2 highlights the twenty most frequently occurring keywords. The proximity of the keywords "Curricula," "Students," "Teaching" and "Engineering Education" aligns with expectation of an association between these topics. However, it is also possible to draw conclusions about the association of other keywords based

Table 3

Keyword co-occurrence network characteristics.

\begin{tabular}{lllll}
\hline Network & Nodes & Edges & Largest cluster & Isolates \\
\hline Keyword co-occurrence & 193,452 & $2,791,368$ & 188,107 & 331 \\
\hline
\end{tabular}




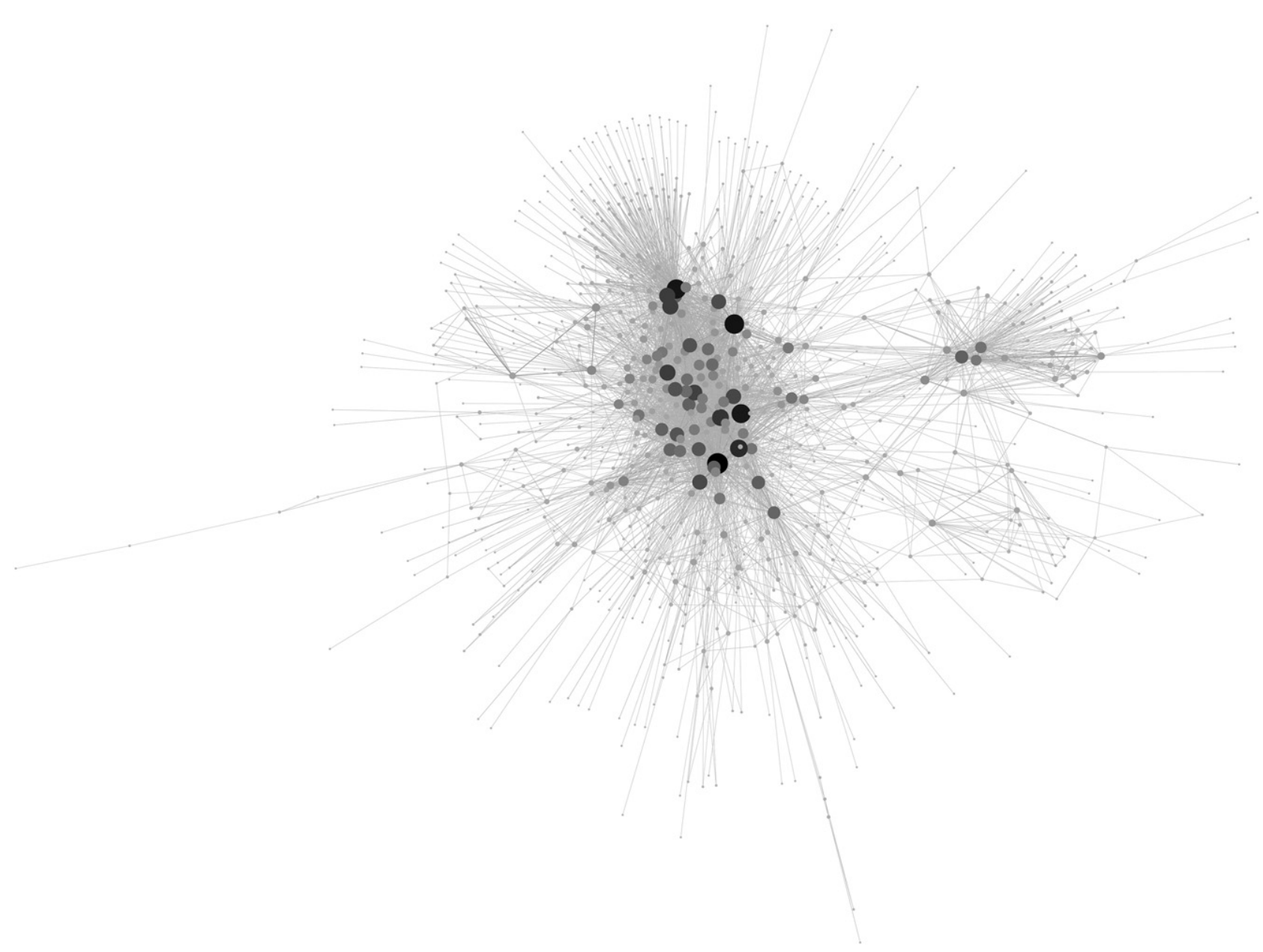

Fig. 1. Keyword co-occurrence network: 1963-2012.

on their placement. For instance, it can be seen that environmental impacts are more commonly associated with construction than for information technology or industrial management. Based on placement, it is also possible to suggest that cost management is more commonly associated with construction than strategic planning, industrial management or software engineering. Issues associated with cost and contract management appear to be highly associated with the construction industry, while issues associated with education appear significantly less associated with these topics. There appears to be less emphasis on cost management in the software and IT industries than in industrial management, strategic planning or construction. Although review of the construction literature reveals a growing interest in Building Information Modelling, it appears that there remains a considerable divide between research which focuses on the construction industry and computer software. The significance of marketing and strategic planning to PM is also of note, as is the crossindustry prominence of decision making in PM research.

It should be noted that this network is an aggregate representation of the field, a static representation of a dynamic process that has not taken account of changes in the ways that terms are used. Visualisations of the network at different periods would produce a structurally different network, showing different relationships between keywords. Keyword Co-Occurrence taken in isolation can also lead to misinterpretation if taken out of context. For instance, it can be seen that keywords related to software are positioned closely to keywords related to education. An initial interpretation may suggest that education is of greater importance to the software industry than construction. However, it is also possible to attribute this proximity between the keyword groups to the use of software in project management education. It would be necessary to refer to the individual articles using these keywords to resolve this.

\section{Keyword burst detection}

Keyword frequency analysis and visualisation through network mapping provide some insight into a field. However, frequency analysis provides little indication of when these keywords became important, and particularly the relative change of significance between keywords over time. Changes in relative frequency over time can be understood through the technique of burst detection, a function in $\mathrm{Sci}^{2}$ based on Kleinberg's Bursty and Hierarchical Structure in Streams (Kleinberg, 2003). Burst detection can be used to detect emergent trends in publication, and has been used in this study to show rapid changes in keyword use. 


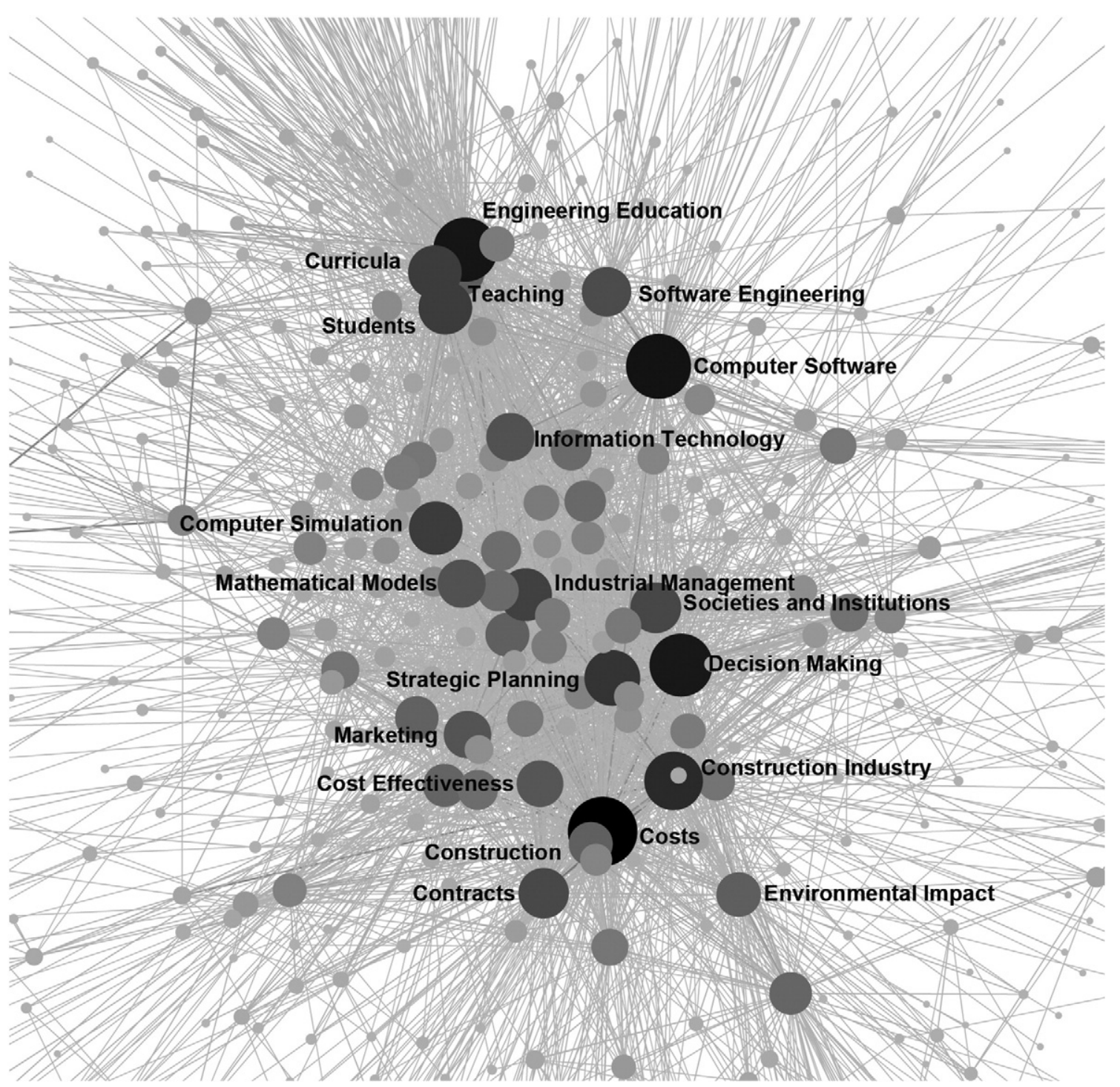

Fig. 2. Top 20 keywords by frequency: 1963-2012.

The burst detection algorithm reveals unusually large changes in the frequency of a datum over time. For example, the word "internet" was barely part of the common the vocabulary until recently. Then, in the second part of the 1990s there was a strong growth in internet use. The language associated with the internet, could be thought of as bursting during that time. The term "internet" is now common, and although of a relatively high frequency compared to in the early 1990s, the term would no longer be considered to be bursting, having reached something more of a steady state.

Fig. 3 is a visualisation of the burst analysis of the keywords in the full data set from 1963 to 2012, showing the top twenty bursting keywords, as sorted by the burst weight. The line thickness indicates the strength of the burst during that period. It is important to remember that burst detection shows rapid change in frequency, not total frequency, so something may burst in popularity, but still remain less significant than consistently high frequency terms.
From Fig. 3 it can be seen that the burst in engineering related keywords continues from 1963 to 1995 . Given the claims of previous research that the basis of project management is in engineering related industries (e.g. Carden \& Egan, 2008; Söderlund, 2004b) this is not surprising, as results around the topics of cost and contracts are. Of more interest are bursts in social impacts, environmental issues and strategic planning in the 1990s. This may indicate a movement away from the technical aspects of project management, lending weight to arguments about a possible paradigm shift in PM research (e.g. Pollack, 2007), potentially indicating a change from an inward technical focus to a broader organisational emphasis. This may also be partly due to an increase in regulation of environmental and social impacts of projects in recent years.

Another group of bursts is apparent in the late 1990s, persisting through to 2005, focusing on aspects of education. This may be attributed to the growth of project management professional associations, the increasing significance of certification as a 


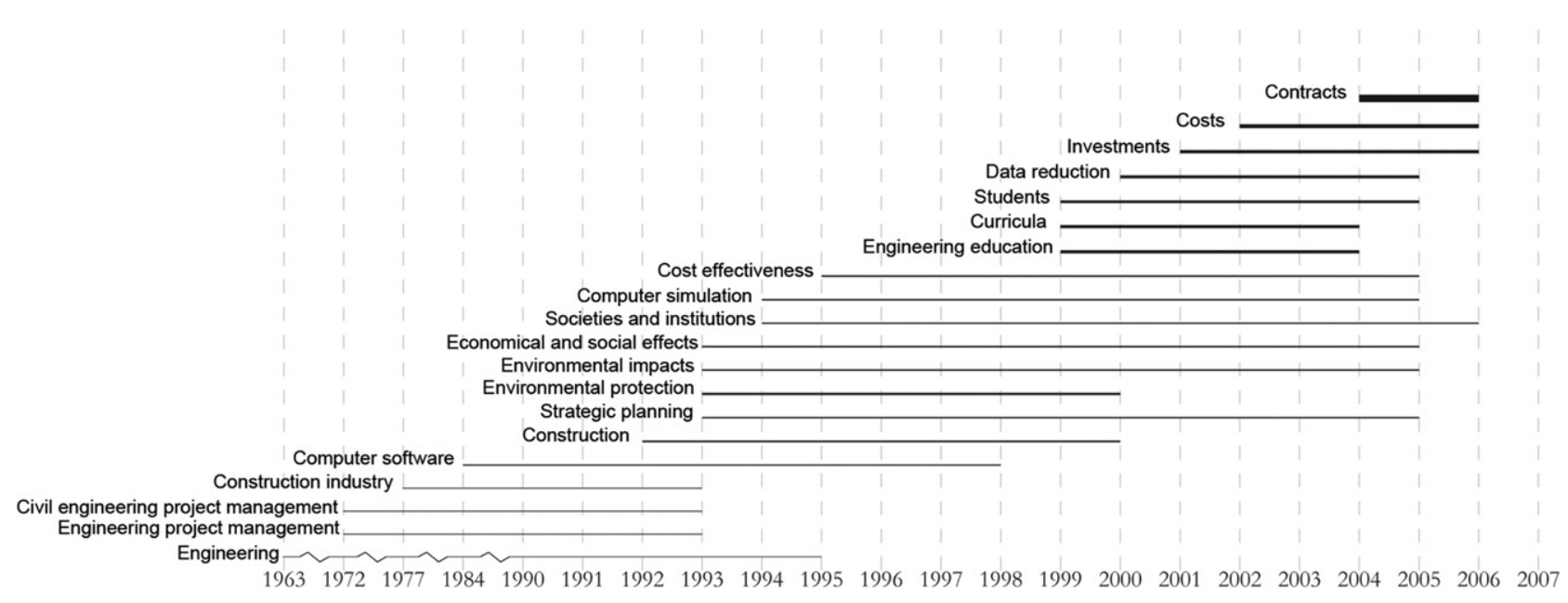

Fig. 3. Top 20 bursting keywords: 1963-2012.

route to employment, and the widespread increase in university education focused on developing the capabilities of project managers.

It is also worth noting that there are no bursting keywords after 2006 in Fig. 3 in the top 20. The hypothesis that there have been no new topics of interest in project management research since 2006 can be rejected through reference to the yearly frequency of publication within the data set (Fig. 4). Publications frequency in the data set peaked in 2004, declining from 2005 to 2012. Assuming a steady rate of keywords per publication, a reducing publication frequency in the last few years of the data set would mean that keywords from this period would be relatively less likely to be identified as bursting.

In response, a second burst analysis from 2006 to 2012 was conducted to understand more recent developments (Fig. 5). Bursting keywords such as "Research," "International conference," "Research projects," and "Case study" in this latter period may instead indicate an increase in interest in legitimising project management as a separate field of research, with a significant number of recent research papers making direct enquiry into this process (e.g. Biedenbach \& Müller, 2011; Smyth \& Morris, 2007; Söderlund, 2004b; Winter et al., 2006). A second explanation, particularly for the keyword "International Conference," may relate to an increase in the frequency of journals featuring special editions composed of selected papers from conferences. However, the data did not allow for testing of this hypothesis.

Keywords such as "Business and economics" and "Knowledge management" may also lend further weight to the idea of an

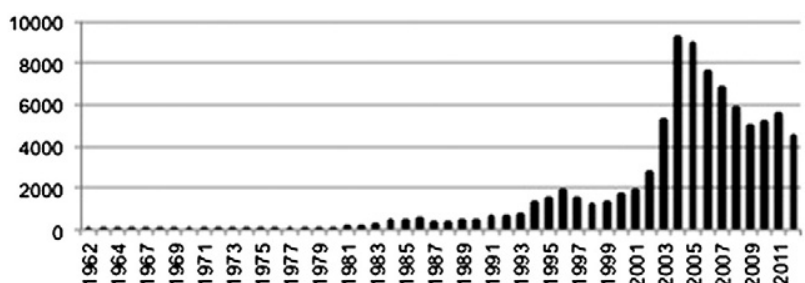

Fig. 4. Total publications per year. increasing organisational focus in recent years, while "Innovation" and "New product development" suggest that project management is more recently being viewed as a potential way of driving or managing change and innovation within organisations. The recent burst of "Project managers" as a keyword could be related to an increasing focus on the competencies required to act in the role, or a shift from a mechanistic perspective which considers the role of project manager as interchangeable and thus not of interest, to one which acknowledges the impact of the embodied experience of individual project managers. Alternatively, or in addition, this burst could indicate a changing perspective on who can know about the activity of project management, suggesting a movement from a de-personalised objectivist approach to research to one which favours local inter-subjectivity.

\section{Abstract term frequency and burst analysis}

Due to computational limitations at the time of processing, it was not possible to construct a network based on the co-occurrence of terms in abstracts in the whole data set for the complete time period. However, a frequency analysis of terms in abstracts was conducted. The truncated version of words in used in the abstracts was used to account for different forms of the same word or meaning. The process of identifying relevant high frequency terms required some interpretation, as the abstracts contained many words that were not directly indicative of any emphasis in project management research, while many others needed to be read in context to understand their relevance. Terms in the abstracts were excluded when they served a structural role in the abstracts, rather than indicating something particular about the research topic. Terms were also excluded when a random sampling of the term read in context revealed that it was being used with considerable inconsistency, and where the project management specific uses of the term were a minority of these cases. For instance, an initial review of the term "Program" placed it as the twentieth most frequent term. However, in context, the term appeared to more frequently indicate a research program, a software program, education or quality programs, than program management. 


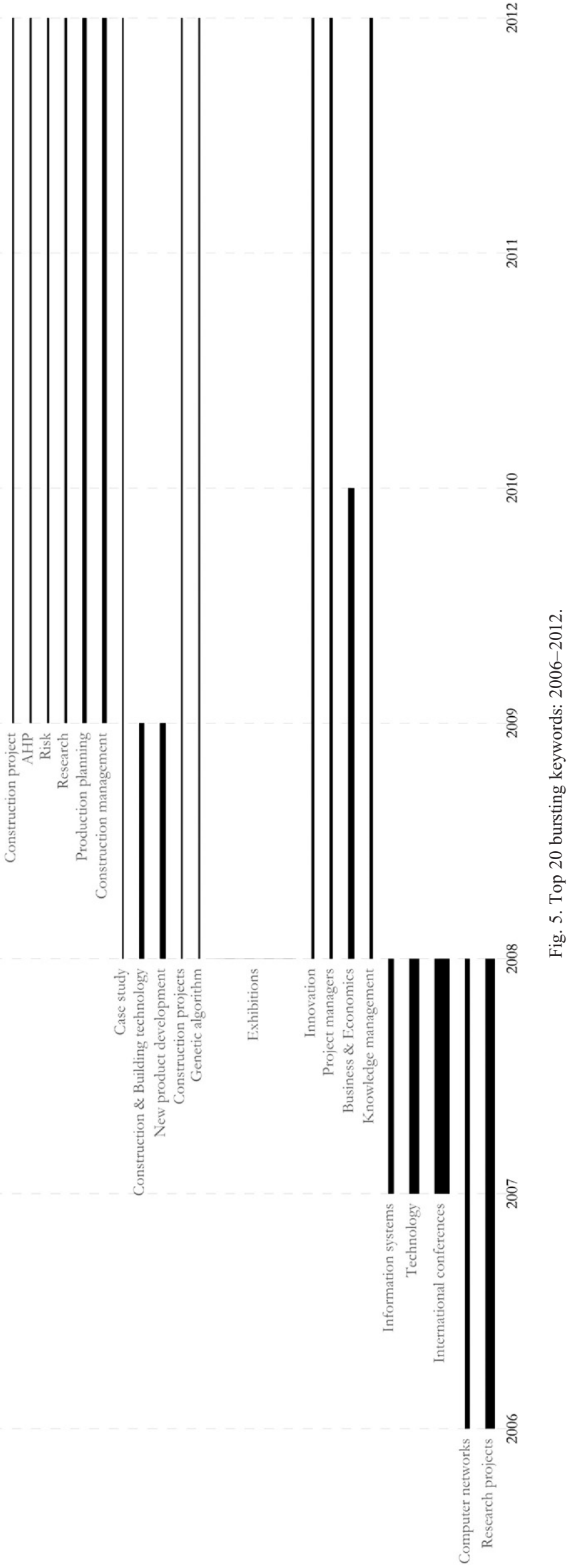


Fig. 6 show the burst analyses for the complete time period. Results have been left in their normalised form, to allow for reader interpretation. Given the similarity in results between burst analyses from the full data set and the 2006 to 2012 period, only the results for the full data set have been provided in graphical form. The similarity of results for burst analyses for 1962-2012 and 2006-2012 is in contrast to results found for the keyword burst analysis. This suggests that the bursts identified in the 1962-2012 period that occurred after 2004 are particularly strong, strong enough to overcome a declining total yearly word count, assuming a relatively consistent average abstract length over the complete time period.

The results of the four burst analyses and two frequency analyses for keywords and abstracts have been combined in Table 4, for ease of comparison. Frequencies have been listed starting with the highest frequency. Bursts have been listed starting with the strongest burst in each time period.

Comparison of keyword frequencies and bursts provides a number of findings. Some keywords demonstrated a high frequency, but did not occur in the top 20 bursting terms from 1963 to 2012, including some of the highest frequency keywords: "Industrial management," "Mathematical models," "Marketing," "Information technology," "Teaching," and "Decision Making." This suggests that these keywords have experienced a steady increase in popularity over the period, and also indicates that these keywords represent some of the consistent considerations of PM research. It is also worthwhile to note that of the Project Management Institute's ten knowledge areas (PMI, 2013) only "Cost" is represented in the frequency or burst analysis, although procurement is represented indirectly through the keyword "Contracts." This may raise questions about alignment between this popular guide and prevailing trends within the field as a whole.

The following keywords were identified in the 1963-2012 burst analysis, but not as amongst the most frequent overall keywords: "Engineering," "Engineering project management," "Civil engineering project management," "Economical and social effects," and "Investment." Of particular interest are the first three engineering related keywords, each of which experienced a burst sustained for longer than any other keyword, and are arguably descriptive of some of the core origins of project management. Their low frequency can be related to the low number of publications in the early years of the data set. This example demonstrates that a frequency analysis alone can misrepresent the influence of keywords, particularly during formative low frequency periods, and should be accompanied by additional techniques such as burst analysis.

Reviewing the terms used in article abstracts provides a different but complementary picture, with greater variation between the burst and frequency analyses, with only three terms occurring in both lists: "Model," "Method," and "Practic." From the most frequent terms used in the abstracts, we can see a broad focus on process, methods and models for project management. Evidence of the primary areas of application for the field can also be seen through the terms, Industries/al, Construction, Engineering, Design, Information, System, and Technology. Other frequent terms indicate a focus on practice, implementation, success, requirements, productivity, planning and control, along with indicators of the standard measures for project success of time, cost and performance.

\section{Evanescent emphases in project management research}

As identified above, the focus of project management research continues to change. Starbuck $(2009$, p. 108) has noted that the "...history of the behavioural and social sciences contains endless sequences of conceptual and methodological fads." There appears little reason to suggest that project management research and researchers would be immune to the social forces which contribute to adoption and rejection of fashionable ideas and conceptual frameworks. As such, further analysis was conducted to understand whether specific bursting terms represent fads or fashions in project management research.

Abrahamson (2009, p. 237) has identified a wide variety of possible reasons for growth and decline in the popularity of areas of research and research techniques, but also notes that identifying a research area as a fad "...easily undermines this areas' and its scholars' perceived importance and authority" (2009, p. 238). It should be noted that both identification of reasons for the growth or decline in frequency of specific keywords or abstract terms, and comment on the promise of specific areas of enquiry, both remain out of scope for this research.

In response, the term "evanescent emphasis" will be used to refer to an area of research enquiry that while once popular, has gone out of fashion as an area of inquiry, declining in frequency to a near negligible proportion of its prior frequency. Terms which decline in frequency, but remain as frequently occurring areas of enquiry have not been classified as an "evanescent emphasis."

The burst analysis results were used as possible indicators of the ascendancy of new trends, before a more detailed frequency analysis was conducted. The terms "cours," "student" and "societi" were all identified as terms in the abstracts with bursts that had ended, and so could represent evanescent emphases in research. Fig. 7 depicts the frequency with which these terms occurred in the abstracts per year. Yearly variation is taken into account by representing the results as a fraction of total publications per year. In each case, the term peaked then declined in popularity, before showing a moderate increase in recent years. The abstract data therefore suggests that while a focus on education and professional societies may have been more dominant areas of research than recently, they remain popular.

Review of the keyword burst analyses presents a more complex picture. The following keywords were selected for further enquiry as recent bursts in the 1962-2012 burst analysis (Fig. 3): "Curricula," "Students," "Costs," "Contracts," and "Investment." Fig. 8 depicts the change in frequency of these keywords, as a percentage of the total publications per year. "Students" and "Curricula" peaked in popularity as keywords in 2001 , occurring in $12 \%$ and $16 \%$ of articles respectively, before declining to $2 \%$ and $1 \%$ of articles in 2012 . This data suggests an evanescent emphasis from approximately 1999 to 2005 for research into project management education. The keywords 

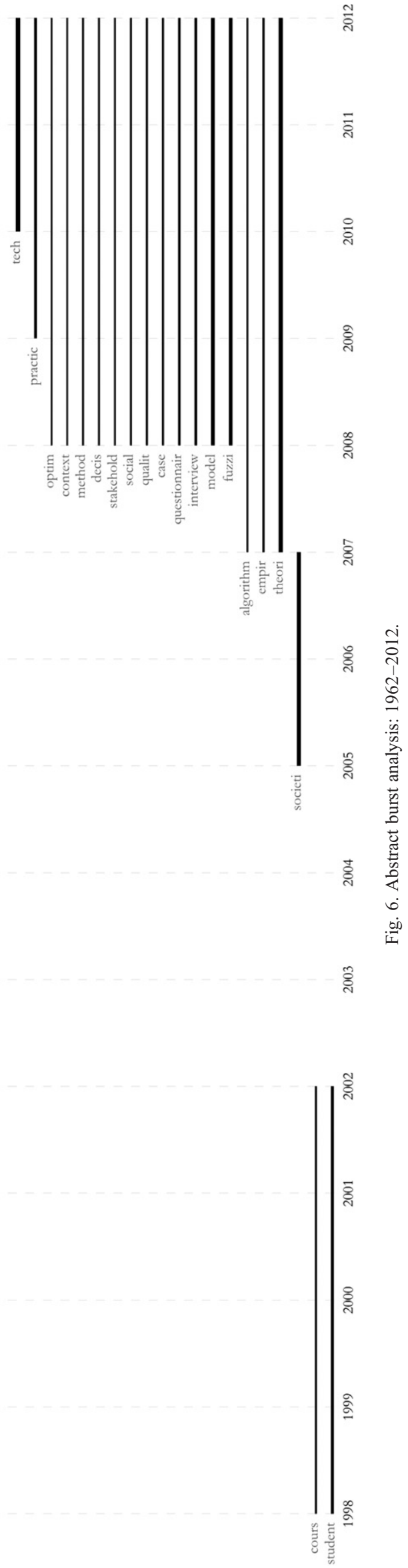
Table 4

Top 20 results of keyword and abstract analyses.

\begin{tabular}{|c|c|c|c|c|c|c|}
\hline \multirow[t]{3}{*}{ No. } & \multicolumn{3}{|l|}{ Keywords } & \multicolumn{3}{|l|}{ Abstracts } \\
\hline & Frequency & Burst & Burst & Frequency & Burst & Burst \\
\hline & $1962-2012$ & $1962-2012$ & $2006-2012$ & $1962-2012$ & $1962-2012$ & $2006-2012$ \\
\hline 1 & Costs & Engineering project management & Research projects & Process & Theori & Theori \\
\hline 2 & Decision making & Engineering education & International conferences & Design & Fuzzi & Fuzzi \\
\hline 3 & Computer software & Civil engineering project management & Construction management & Model & Model & Model \\
\hline 4 & Engineering education & Costs & Knowledge management & Construct & Student & Student \\
\hline 5 & Construction industry & Construction & Business and economics & Engin & Empir & Empir \\
\hline 6 & Strategic planning & Curricula & Project managers & Requir & Interview & Interview \\
\hline 7 & Students & Strategic planning & Production planning & Product & Questionnair & Questionnair \\
\hline 8 & Curricula & Cost effectiveness & Innovation & Technolog & Algorithm & Algorithm \\
\hline 9 & Contracts & Students & Computer networks & Time & Tech & Tech \\
\hline 10 & Industrial management & Engineering & Technology & Method & Case & Case \\
\hline 11 & Software engineering & Investments & Research & Perform & Qualit & Qualit \\
\hline 12 & Computer simulation & Societies and industry & Exhibitions & Inform & Societi & Practic \\
\hline 13 & Societies and institutions & Construction industry & Genetic algorithm & Cost & Practic & Cours \\
\hline 14 & Information technology & Environmental protection & Construction projects & Plan & Cours & Social \\
\hline 15 & Marketing & Computer simulation & Risk & Industri & Social & Stakehold \\
\hline 16 & Environmental impact & Environmental impact & New product development & System & Stakehold & Decis \\
\hline 17 & Cost effectiveness & Contracts & AHP & Implement & Decis & Method \\
\hline 18 & Construction & Economic and social effects & Construction and building technology & Success & Method & Context \\
\hline 19 & Mathematical models & Data reduction & Case study & Practic & Context & Optim \\
\hline 20 & Teaching & Computer software & Information systems & Control & Optim & Practition \\
\hline
\end{tabular}

"Cost," "Contracts" and "Investment" peaked in popularity in 2004 , occurring in $12 \%, 8 \%$ and $7 \%$ of articles, before receding to $3 \%, 1 \%$ and $1 \%$ of articles in 2012 . This suggests a similarly evanescent emphasis from approximately 2001 to 2006 for research into these topics.

The following keywords were selected for further enquiry as recent bursts in the 2006-2012 burst analysis (Fig. 9): "Information systems," "Computer networks," "New product development," "Business and economics," "International conferences," and "Research projects." Use of "Computer networks" as a keyword peaked in 2008 at $4 \%$ of articles, while "Information systems" was used as a keyword in $8 \%$ of articles in both 2008 and 2010. Both "New product development" and "Business and economics" peaked as keywords in 2009 at 3\% and 4\% respectively, while the research related keywords "International conferences" and "Research projects" were used in 3\% and $6 \%$ of articles in 2008 respectively. All of these keywords were used in less that $1 \%$ of articles in 2012, suggesting that the fashion of using these terms as keywords has ended.

It should be noted that this analysis of abstracts and keywords has examined changes in the use of specific terms, rather than the concepts that these terms may signify. Over time, the ways in which terms are used may change, and different areas of specialisation may use different terms to refer to a similar concept. Where a group of terms signifying a similar concept trend in a comparable way, such as with the terms "curricula," "students" and "course" it is reasonable to draw a broad conclusion about a trend in PM research. However, when a trend in a term is taken in isolation, it is possible that the trend indicates a change in the way the concept is being discussed as much a change in its centrality to PM research.

Given that this research has drawn upon a broad range of sources from the complete ISI WoS and Scopus databases, it is worthwhile to briefly consider whether project management

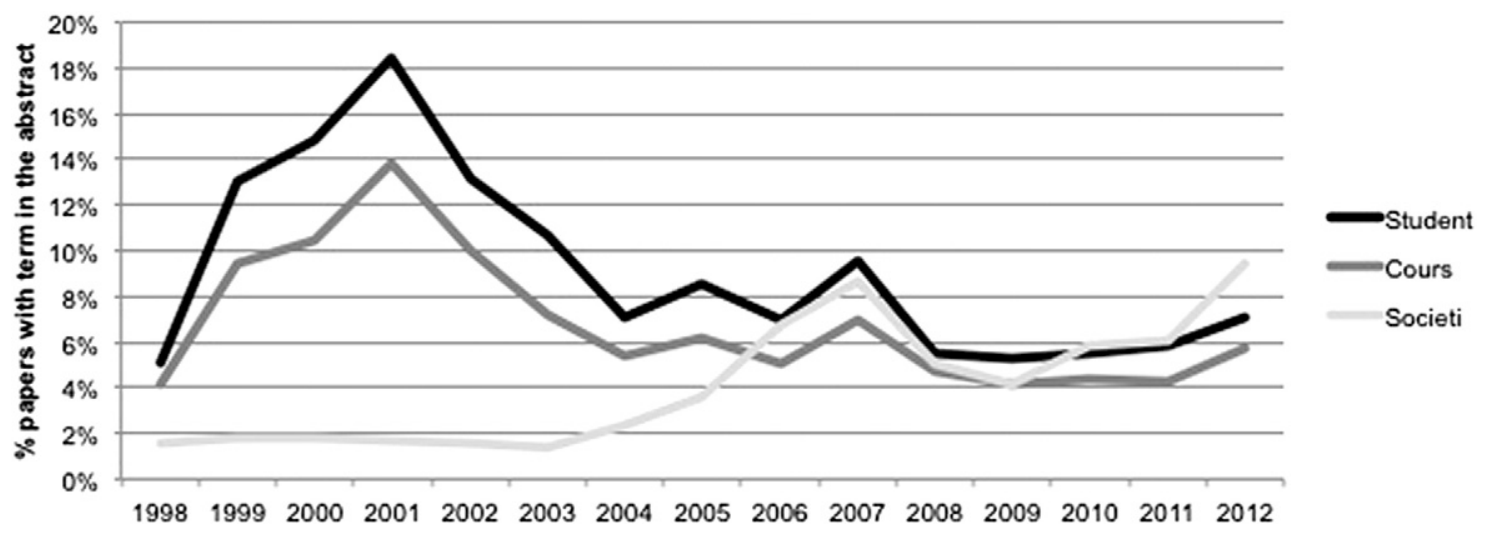

Fig. 7. Evanescent emphases in abstracts. 


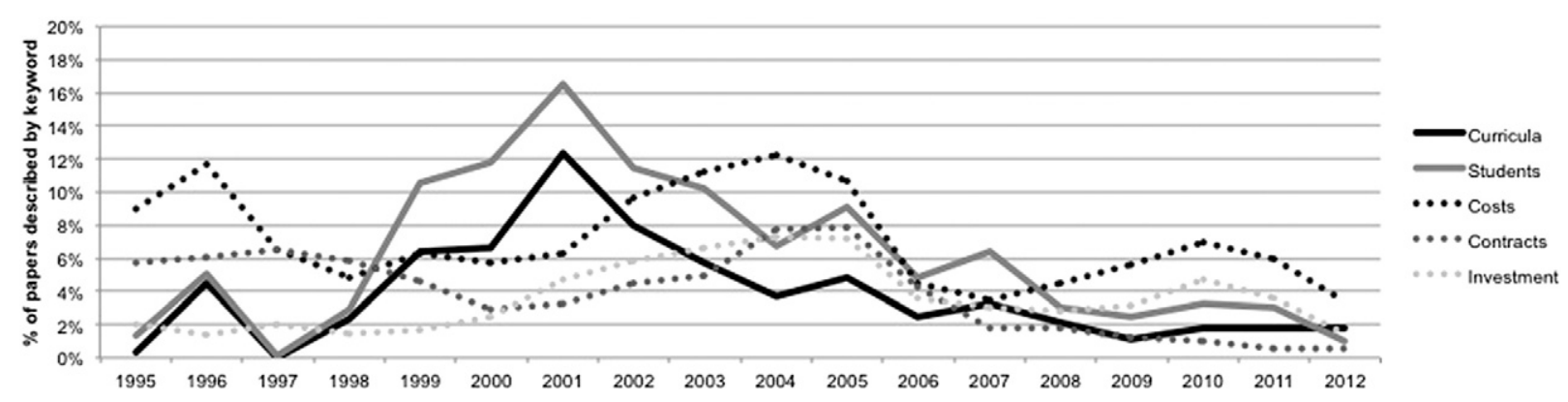

Fig. 8. Evanescent emphases in keywords (1962-2012).

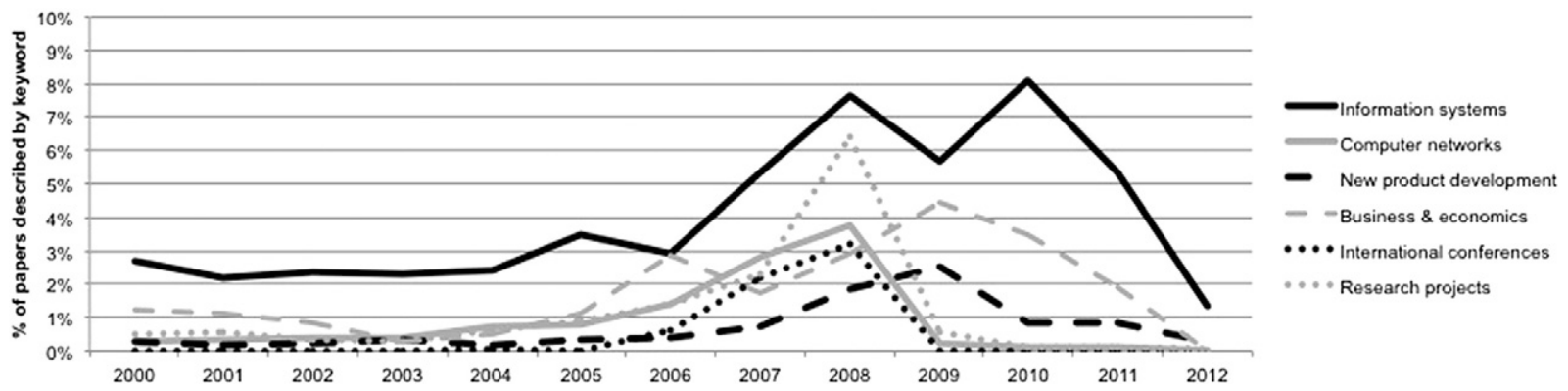

Fig. 9. Evanescent emphases in keywords (2006-2012).

research itself exhibits any fad-like qualities. Reflecting back to Fig. 4 the total number of project management related publication exhibited a low but steady increase from 1962 to the early 1990s, before a rapid expansion and peak in 2004. Since 2004, articles related to project management have declined in frequency in the data set, but appear to have settled at a new and significantly more prominent steady state from 2007 to 2012 at a significantly higher plateau than before 2002 . As project management research does not appear to be declining into the obscurity typically associated with the latter stages of a fad life-cycle, the data available at this time suggests that research into project management is not a fad.

\section{Conclusion}

This research has drawn findings from 94,472 unique records, comprised of research publications in the ISI and Scopus databases, in response to the search term "project management." This research has used a variety of techniques to analyse changes in PM research published between 1962 and 2012, including network analysis, frequency analysis and burst detection, applied to publication keywords and abstracts. Burst detection has confirmed other authors' observation of the influence of engineering on the early development of the field. However, more recent bursts in research described with keywords related to environmental issues, strategic planning, project managers, knowledge management, business and innovation suggest a movement from technical and industry-specific issues to an emphasis on the interpersonal aspects of project management and the role of the field in the broader organisational context. In addition, recent bursts in research-related keywords suggest an increasing focus on PM as an independent field of research.

A variety of evanescent emphases can also be seen in PM research publications, particularly in keyword use. Use of keywords related to education enjoyed a period of popularity from 1999 to 2005, while keywords related to cost, contracts and investment were popular from 2001 to 2006, before declining in frequency. Keywords related to computer networks and information systems were popular from 2008 to 2012, while specific keywords related to new product development and economics were popular from 2009 to 2012.

Based on the frequency of keyword co-occurrence, the network analysis has revealed that issues associated with decision making are central to PM research, through the frequent co-occurrence of decision making with other keywords. Keywords related to cost and contract management have been found to be more strongly associated with the construction industry than the IT industry, while issues associated with education have been more strongly associated with IT than construction.

Methodologically, this research has also shown that exclusively focusing on frequencies in keyword analysis has limitations, and should be tempered by an understanding of the relative change in emphasis over time, such as can be gained through burst analysis. Evidence for this can be seen in the persistent early burst in engineering related keywords, which helped to set the early assumptions on which the field is based; keywords which do not show up in frequency analysis.

\section{Conflict of interest}

There is no conflict of interest. 


\section{Acknowledgement}

This paper is based on an earlier paper by the same authors presented at the IRNOP 2013 Conference, Oslo, Norway.

\section{References}

Abrahamson, E., 2009. Necessary conditions for the study of fads and fashions in science. Scand. J. Manag. 25, 235-239.

Artto, K., Martinsuo, M., Gemünden, H.G., Murtoaro, J., 2009. Foundations of program management: a bibliometric view. Int. J. Proj. Manag. 27 (1), 1-18.

Betts, M., Lansley, P., 1995. International Journal of Project Management: a review of the first ten years. Int. J. Proj. Manag. 13 (4), 207-217.

Biedenbach, T., Müller, R., 2011. Paradigms in project management research: examples from 15 years of IRNOP conferences. Int. J. Manag. Proj. Bus. 4 (1), 82-104.

Börner, K., 2007. Making sense of mankind's scholarly knowledge and expertise: collecting, interlinking, and organizing what we know and different approaches to mapping (network) science. Environ. Plan. B Plan. Des. 34, 808-825.

Börner, K., 2010. Atlas of Science: Visualizing What We Know. MIT Press, London.

Börner, K., 2012. Picturing science. Nature 487, 430-431.

Carden, L., Egan, T., 2008. Does our literature support sectors newer to project management? The search for quality publications relevant to nontraditional industries. Proj. Manag. J. 39 (3), 6-27.

Chen, C., Fang, S., Börner, K., 2011. Mapping the development of scientometrics: 2002 to 2008. J. Libr. Sci. China 3, 131-146.

Crawford, L., Pollack, J., England, D., 2006. Uncovering the trends in project management: journal emphases over the last 10 years. Int. J. Proj. Manag. 24 (2), 175-184.

Elsevier, 2013. What does Scopus cover?. Retrieved 15 January, 2013, from http://www.info.sciverse.com/scopus/scopus-in-detail/facts.

Frick, A., Ludwig, A., Mehldau, H., 1994. A fast adaptive layout algorithm for undirected graphs. In: Tamassia, R., Tollis, I. (Eds.), Proceedings of the DIMACS International Workshop on Graph Drawing, pp. 388-403.

Hanisch, B., Wald, A., 2012. A bibliometric view on the use of contingency theory in project management research. Proj. Manag. J. 43 (3), 4-23.

Hook, P., 2007. Domain maps: purposes, history, parallels with cartography, and applications. Presented at the 11th Annual Information Visualization International Conference, pp. 442-446.

Hook, P., Börner, K., 2005. Educational knowledge domain visualizations: tools to navigate, understand, and internalize the structure of scholarly knowledge and expertise. In: Spink, A., Cole, C. (Eds.), New Directions in Cognitive Information Retrieval, pp. 187-208.

Kleinberg, J., 2003. Bursty and hierarchical structure in streams. Data Min. Knowl. Disc. 7 (4), 373-397.

Kloppenborg, T., Opfer, W., 2002. The current state of project management: trends, interpretations, and predictions. Proj. Manag. J. 33 (2), 5-18.

Kwak, Y., Anbari, F., 2009. Analyzing project management research: perspectives from top management journals. Int. J. Proj. Manag. 27, 435-446.

Pollack, J., 2007. The changing paradigms of project management. Int. J. Proj. Manag. 25, 266-274.

Project Management Institute (PMI), 1996. A Guide to the Project Management Body of Knowledge. Project Management Institute, Newtown Square, PA.

Project Management Institute (PMI), 2013. A Guide to the Project Management Body of Knowledge. Project Management Institute, Newtown Square, PA.

Scharnhorst, A., 2012. Preface. In: Scharnhorst, A., Börner, K., van de Besselaar, P. (Eds.), Models of Science Dynamics: Encounters Between Complexity Theory and Information Science, pp. xi-xix.

Sci2-Team, 2009. Science of Science (Sci2) Tool. http://sci2.cns.iu.edu (Indiana University and SciTech Strategies).

Smyth, H., Morris, P., 2007. An epistemological evaluation of research into projects and their management: methodological issues. Int. J. Proj. Manag. $25,423-436$

Söderlund, J., 2004a. Building theories of project management: past research, questions for the future. Int. J. Proj. Manag. 22, 183-191.

Söderlund, J., 2004b. On the broadening scope of the research on projects: a review and a model for analysis. Int. J. Proj. Manag. 22, 655-667.

Söderlund, J., 2011. Pluralism in project management: navigating the crossroads of specialization and fragmentation. Int. J. Manag. Rev. 13, 153-176.

Starbuck, W., 2009. The constant causes of never-ending faddishness in the behavioral and social sciences. Scand. J. Manag. 25, 108-116.

Themistocleous, G., Wearne, S., 2000. Project management topic coverage in journals. Int. J. Proj. Manag. 18, 7-11.

Thompson-Reuters, 2012. Web of science. Retrieved 1 April, 2012, from http://apps.webofknowledge.com.ezproxy.lib.uts.edu.au/WOS_ GeneralSearch $\_$input.do?product $=$WOS\&search $\_$mode $=$GeneralSearch\&SID $=$ P1pM86Fg6nc89nEC6hE\&preferencesSaved $=\% 3 \mathrm{E}$.

Urli, B., Urli, D., 2000. Project management in North America, stability of the concepts. Proj. Manag. J. 31 (3), 33-43.

Winter, M., Smith, C., Morris, P., Cicmil, S., 2006. Directions for future research in project management: the main findings of a UK governmentfunded research network. Int. J. Proj. Manag. 24, 638-649.

Zobel, A., Wearne, S., 2000. Project management topic coverage in recent conferences. Proj. Manag. J. 31 (2), 32-37. 